\title{
Fuzzy Evaluation Model Construction of Performance Management
}

\author{
Xiaoyue Wang ${ }^{1, a^{*}}$, Haixu Xi ${ }^{1, b}$, Xinping Hong ${ }^{2, c}$ and Lijuan Gao ${ }^{3, d}$ \\ ${ }^{1}$ Jiangsu University of Technology, Changzhou Jiangsu 213001, China \\ ${ }^{2}$ Wuxi Higher Vocational School of Tourism and Commerce, Wuxi Jiangsu 214046, China \\ ${ }^{3}$ Changzhou Vocational School of Industry and Trade, Changzhou Jiangsu 213012, China \\ awxy1984@jsut.edu.cn, b546485705@qq.com, '918964388@qq.com, d781760189@qq.com \\ *The corresponding author
}

Keywords: Performance evaluation; Comprehensive fuzzy evaluation; Evaluation model; Functional department of colleges and universities

\begin{abstract}
The Performance Evaluation System of functional departments in colleges and universities displays the features like multi-index, multi-attribute, concrete together with fuzzification. To avoid the defect developed by the simple combination of qualitative index and quantitative index in the Performance Evaluation, use universal fuzzy evaluation to construct the evaluation model of performance management, quantifying the index, quantifying the evaluation result by mathematic model, making the evaluation result objective, scientific and specific.
\end{abstract}

\section{Introduction}

Performance evaluation, to an organization, is a suit of methods to smooth the strategy implementation capability, combining dynamically the personal performance, individual development and organization goal together, instantly improving the organization performance through the development of individual performance and group performance, finally guaranteeing the practice of organizational strategy and the realization of professional goal.

Performance evaluation is the fundament of performance management for an organization, performance evaluation index with the features like concreteness and periodicity, easy to be conducted and realized in practice. The aim of this thesis is to employ the quantitative approach to establish a performance evaluation model of functional departments in colleges and universities. Comprehensive fuzzy evaluation is selected as the evaluation methodology, weight identification for each evaluation factor using analytic hierarchy process(AHP)[1], and then identifying the importance of each index in the entire evaluation system.

\section{Principles of Model Establishment}

Performance evaluation of functional departments in colleges and universities is very complex, affecting by various factors, referring to the quantitative index evaluation and the qualitative index. Comprehensive fuzzy evaluation is originated from the comprehensive evaluation method of fuzzy mathematics, capable of coping with the issue which is hard to quantize, suitable to settle the uncertainty issues [2] [3]. When set up the index system, the following principles are supposed to be obeyed:

System principle: due to the particularity of the products of colleges and universities, the selected index ought to be with the feature of foresight. Focus on the evaluation aim, which should be able to reflect the output efficiency and benefit of financial investment. Since the relevance universally existing among each factor, the quantity of factors ought to be stressed, reflecting the overall allocation state from multi-level and multi-view.

The combination of precision and fuzziness: some index can be calculated precisely, while some only can be described by tend or direction, the identification of index system, the selection of index and the 
derivation of formula all requiring scientific supports.

Comparability principle: the identification of performance evaluation index is not only suitable for one or some colleges and universities, but also for all colleges and universities. Therefore, the index setting of the identical system is supposed to be with the comparability for individual institute.

Maneuverability principle: the index system of performance evaluation aims to be simple, convenient and applicable, with sharp selecting concept and clear definition. It is easy to collect and calculate, and with applicability and maneuverability in terms of practice.

\section{Construction of Fuzzy Evaluation Model}

From the perspective of the service object and the service content of the functional departments in colleges and universities, the differences among various functional departments are apparently, some focusing on students, some stressing on faculty, and meanwhile some are in charge of the administration of the faculty and the students [4]. Obviously, different types of functional departments ought to be evaluated by different performance evaluation systems. Hereby, taking the functional department, which is in charge of the administration of the faculty and the students, as an instance, illustrate the performance evaluation systems. In this thesis, there are five factors selected as the index in performance evaluation system: the performance of duty, the cooperation with other departments, student training and employment, teacher achievement and training, teaching performance (displayed in Table 1). The mathematical set of performance evaluation factors is $X=\left\{x_{1}, x_{2}, x_{3}, x_{4}, x_{5}\right\}$.

Table 1 Distribution table of performance evaluation index

\begin{tabular}{|l|l|}
\hline performance evaluation index & \multicolumn{1}{|c|}{ Content of index } \\
\hline performance of duty & $\begin{array}{l}\text { The completion state of the quantity and quality of the } \\
\text { duties, including the administration of the faculty and the } \\
\text { students in daily life and the teaching work }\end{array}$ \\
$\begin{array}{l}\text { cooperation with other } \\
\text { departments }\end{array}$ & $\begin{array}{l}\text { The coordinate sense and team spirit among different } \\
\text { departments and the effective communication on } \\
\text { management information. }\end{array}$ \\
$\begin{array}{l}\text { student training and } \\
\text { employment }\end{array}$ & $\begin{array}{l}\text { The investment in training (human resource and financial } \\
\text { support and so on) and performance evaluation, } \\
\text { employment rate of student and student satisfaction. }\end{array}$ \\
$\begin{array}{l}\text { teacher achievement and } \\
\text { training }\end{array}$ & $\begin{array}{l}\text { Achievements in scientific research, teaching } \\
\text { performance and teacher training. }\end{array}$ \\
teaching performance & The teaching performance and student satisfaction of \\
\hline
\end{tabular}

In view of the fuzziness existed in our cognations and judgments, the principle employed in this thesis combines the precision and fuzziness together, evaluating each index separately, classifying the results into five ranks, that is, excellent, good, fine, qualified and poor, establishing the set of performance evaluation results $N=\left\{n_{1}, n_{2}, n_{3}, n_{4}, n_{5}\right\} \cdot A=\left(a_{i j}\right)(i=1,2, \cdots, 5, j=1,2, \cdots 5$,$) is a single$ 
factor evaluation matrix, suggesting that the fuzzy relation from $M$ to $N, a_{i j}$ representing the possible result of the $i$ th evaluation object affected by the $j$ performance evaluation index. Calculate $B=M A$, and hereinto $M=\left\{m_{1}, m_{2}, m_{3}, m_{4}, m_{5}\right\}$ is the weight set of performance evaluation index. Then, according to these five performance evaluation index, identify the weight of each one, and then process the comparison evaluation among the overall results of the evaluation object and the results of each index [5].

\section{Data Collection}

Randomly select 200 people from the faculty and the students from a university, collecting the data mainly through interview survey and questionnaire, focusing on the performance management states of School of Science, School of Economics and Management and Architectural and Civil Engineering School. There are following five aspects are evaluated, listed in the Table 2. The evaluation result of each index is classified into five ranks, that is, excellent, good, fine, qualified and poor, and the weight of each index is also calculated [6]. Taking School of Science as an example, the evaluation results are as follows (Table 2):

Table 2 Evaluation result [\%]

\begin{tabular}{|l|c|c|c|c|c|}
\hline School of Science & excellent & good & fine & qualified & poor \\
\hline performance of duty & 35 & 43 & 13 & 7 & 2 \\
\hline cooperation with other departments & 48 & 30 & 15 & 5 & 2 \\
\hline student training and employment & 2 & 5 & 21 & 39 & 33 \\
\hline teacher achievement and training & 27 & 16 & 40 & 7 & 6 \\
\hline teaching performance & 60 & 30 & 10 & 10 & 0 \\
\hline
\end{tabular}

The fuzzy evaluation matrix of School of Science can be produced based on the data

$$
A_{1}=\left[\begin{array}{lllll}
0.35 & 0.48 & 0.02 & 0.27 & 0.60 \\
0.43 & 0.30 & 0.05 & 0.16 & 0.30 \\
0.13 & 0.15 & 0.21 & 0.40 & 0.10 \\
0.07 & 0.05 & 0.39 & 0.07 & 0.10 \\
0.02 & 0.02 & 0.33 & 0.06 & 0.00
\end{array}\right]
$$

Adopt the same data collection method to obtain the fuzzy evaluation matrixes of School of Economics and Management and Architectural and Civil Engineering School $A_{2}$ and $A_{3}$ respectively.

$$
\begin{aligned}
A_{2} & =\left[\begin{array}{lllll}
0.36 & 0.17 & 0.10 & 0.29 & 0.44 \\
0.28 & 0.31 & 0.32 & 0.23 & 0.32 \\
0.23 & 0.35 & 0.31 & 0.33 & 0.12 \\
0.08 & 0.07 & 0.21 & 0.10 & 0.10 \\
0.05 & 0.10 & 0.06 & 0.05 & 0.02
\end{array}\right] \\
A_{3} & =\left[\begin{array}{lllll}
0.21 & 0.31 & 0.50 & 0.38 & 0.46 \\
0.24 & 0.28 & 0.22 & 0.32 & 0.27 \\
0.37 & 0.30 & 0.17 & 0.23 & 0.15 \\
0.08 & 0.07 & 0.11 & 0.05 & 0.12 \\
0.10 & 0.04 & 0.00 & 0.02 & 0.00
\end{array}\right]
\end{aligned}
$$




\section{Solution of Model}

The value of each rank is as following, 5, 4, 3, 2, and 1 for excellent, good, fine, qualified and poor respectively in the performance evaluation systems [7], the weight for each grade in the performance evaluation index, as follows:

$$
\begin{aligned}
& M=\frac{\left[m_{1}, m_{2}, m_{3}, m_{4}, m_{5}\right]}{m_{1}+m_{2}+m_{3}+m_{4}+m_{5}}=\frac{[5,4,3,2,1]}{5+4+3+2+1}=[0.33,0.27,0.20 .0 .13,0.07], \text { that is, weight vector is } \\
& M=[0.33,0.27,0.20 .0 .13,0.07] .
\end{aligned}
$$

Evaluation matrix is processed through linear transformation $M A_{1}$, the result of linear transformation of School of Science as follows:

$$
B_{1}=M A_{1}=\left[\begin{array}{lllll}
0.33 & 0.27 & 0.20 & 0.13 & 0.07
\end{array}\right] \bullet\left[\begin{array}{lllll}
0.35 & 0.48 & 0.02 & 0.27 & 0.60 \\
0.43 & 0.30 & 0.05 & 0.16 & 0.30 \\
0.13 & 0.15 & 0.21 & 0.40 & 0.10 \\
0.07 & 0.05 & 0.39 & 0.07 & 0.10 \\
0.02 & 0.02 & 0.33 & 0.06 & 0.00
\end{array}\right]=\left[\begin{array}{lllll}
0.27 & 0.28 & 0.14 & 0.23 & 0.31
\end{array}\right]
$$

With the same method, the linear transformation results of evaluation matrixes of School of Economics and Management and Architectural and Civil Engineering School can be obtained as listed:

$$
\begin{aligned}
& B_{2}=M A_{2}=\left[\begin{array}{lllll}
0.25 & 0.17 & 0.21 & 0.24 & 0.27
\end{array}\right] \\
& B_{3}=M A_{3}=\left[\begin{array}{lllll}
0.23 & 0.25 & 0.43 & 0.27 & 0.26
\end{array}\right]
\end{aligned}
$$

A transformed evaluation matrix can be developed on the basis of the results above:

$$
B=\left[\begin{array}{lll}
0.27 & 0.25 & 0.23 \\
0.28 & 0.17 & 0.25 \\
0.14 & 0.21 & 0.43 \\
0.23 & 0.24 & 0.27 \\
0.31 & 0.27 & 0.26
\end{array}\right]
$$

Assume that the weight of each evaluation index( five indexes) were $N=\left[\begin{array}{lllll}0.2 & 0.1 & 0.2 & 0.2 & 0.3\end{array}\right]$, and then the comprehensive evaluation scores of three schools respective are

$$
C=N B=\left[\begin{array}{lllll}
0.2 & 0.1 & 0.2 & 0.2 & 0.3
\end{array}\right] \bullet\left[\begin{array}{lll}
0.27 & 0.25 & 0.23 \\
0.28 & 0.17 & 0.25 \\
0.14 & 0.21 & 0.43 \\
0.23 & 0.24 & 0.27 \\
0.31 & 0.27 & 0.26
\end{array}\right]=\left[\begin{array}{lll}
0.249 & 0.238 & 0.289
\end{array}\right]
$$

Based on the evaluation matrix B and the weight of each evaluation index, the score of each evaluation index for three schools can be calculated as following method:

$$
D=B^{T} \bullet\left[\begin{array}{lllll}
0.2 & & & & \\
& 0.1 & & & \\
& & 0.2 & & \\
& & & 0.2 & \\
& & & & 0.3
\end{array}\right]
$$




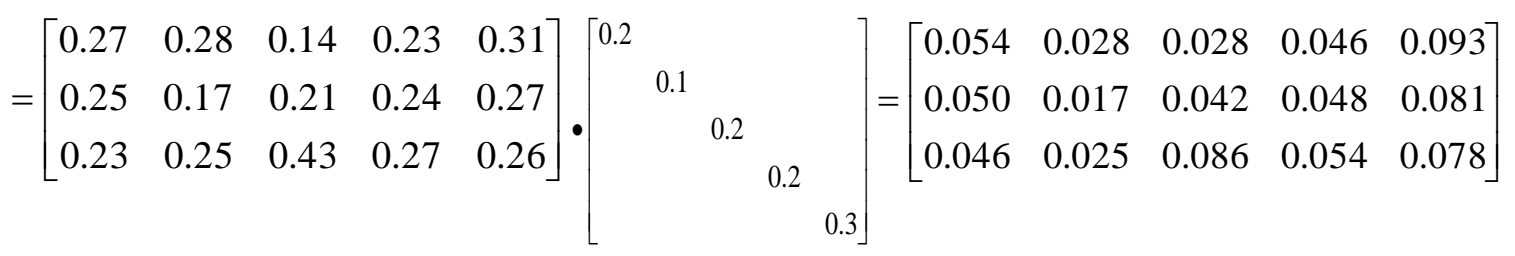

\section{Analysis of Evaluation Result}

In accordance with the calculating results, the scores of each index and the overall scores of three schools can be gained in the performance evaluation (Table 3 ).

Table 3 Individual score and overall score

\begin{tabular}{|l|c|c|c|c|c|c|}
\hline & $\begin{array}{l}\text { Duty } \\
\text { performance }\end{array}$ & Coordination & $\begin{array}{l}\text { Students } \\
\text { administration }\end{array}$ & $\begin{array}{l}\text { Faculty } \\
\text { administration }\end{array}$ & $\begin{array}{l}\text { Teaching } \\
\text { management }\end{array}$ & $\begin{array}{l}\text { Overall } \\
\text { score }\end{array}$ \\
\hline $\begin{array}{l}\text { School of } \\
\text { Science }\end{array}$ & 0.054 & 0.028 & 0.028 & 0.046 & 0.093 & 0.249 \\
\hline $\begin{array}{l}\text { School of } \\
\text { Economics } \\
\text { and } \\
\text { Management }\end{array}$ & 0.050 & 0.017 & 0.042 & 0.048 & 0.081 & 0.238 \\
\hline $\begin{array}{l}\text { Architectural } \\
\text { and Civil } \\
\text { Engineering } \\
\text { School }\end{array}$ & 0.046 & 0.025 & 0.086 & 0.054 & 0.078 & 0.289 \\
\hline
\end{tabular}

From the data comparison in the table, the highest score in the comprehensive evaluation is obtained by Architectural and Civil Engineering School, School of Science ranking the second site. For the duty performance, coordination and teaching management, School of Science is better than the others. However, for the students' administration and faculty administration, Architectural and Civil Engineering School performance better. For student training and employment, Architectural and Civil Engineering School present outstanding advantages than the others. Others aspects related to administration also can employ this method to evaluate.

\section{Conclusion and Suggestion}

This model is with strong reliability, able to be used into other positions and organizations. Colleges and universities should scientifically and reasonably adjust the weight of each relevant factor, making the evaluation system grow perfectly.

Comprehensive fuzzy evaluation is capable of evaluating and judging the person or matter that are influenced by multi-factor and multi-object [8]. It is able to objectively reflect the actual state of evaluation object, better for improve the evaluation criteria of performance evaluation in colleges and universities.

The evaluation system combines the qualitative indexes and quantitative indexes together, making up the defect produced by the simple combination of the qualitative indexes and quantitative indexes, improving the precision of comprehensive evaluation [9].

The reliability and precision of the comprehensive evaluation results count on the identification of rational factors, the weight allocation of factors and the composition operator of comprehensive evaluation and so on. Therefore, when the model is applied into the practice, the weight of each index ought to be adjusted according to the specific situation, making the evaluation much more objective, scientific and specific [10]. 


\section{Acknowledgements}

The work was supported by the modern educational technology research 2015 annual project of Jiangsu Province of China under Grant 2015-R-45347 and natural science foundation of youth project of Jiangsu University of Technology under Grant KYY14018 and higher education research project of Jiangsu University of Technology under Grant KYY15504 and social science foundation of youth project of Jiangsu University of Technology under Grant KYY14534.

\section{References}

[1] J. Wang, M.Y. Zhang, B.W. Jiang, S.L. Zhao and T.Y. Sheng: Design of Comprehensive Environmental Quality Assessment of Fuzzy Comprehensive Evaluation Method and AHP, Journal of Anhui Agricultural Sciences, Vol.42 (2014) No.3, p.860, (In Chinese).

[2] [X.M. Wang and M.R. Chen: University Faculty Comprehensive Evaluation Model Based on the Multivariable Objects, Natural Science Journal of Hainan University, Vol.31 (2013) No.2, p.149, (In Chinese).

[3] K. Sun and T.Y. Song: Application of Fuzzy Comprehensive Evaluation in Bids of Medical Supplies, Modern Instrument and Medical Treatment, Vol.19 (2013) No.1, p.12.

[4] L.X. Ji: A Comprehensive Evaluation System of Configuration Feasibility for Large Medical Equipment, Journal of Chongqing Institute of Technology, Vol.23 (2009) No.8, p.36, (In Chinese).

[5] W.M. Yan and F.Y. Zhou: A Study on Fuzzy Evaluation Techlliques of Performance Conversion for S\&T Achievements in Universities, R\&D MANAGEMENT, Vol.18 (2006) No.6, p.129.

[6] S.F. Qiu: Principle and Application of Sunplus Sixteen Bit Single-chip Microcomputer (Xi'an Electronic and Science University Press, China 2011), (In Chinese).

[7] W. Hu, W.Y. Bai and Y.Z. Qu: Research on Resolving Object Coreference on the Semantic Web, Ruan Jian Xue Bao/Journal of Software, Vol.23 (2012) No.7, p.1729, (In Chinese)

[8] Q. Yan, and C.H Zhang: Research on Fuzzy Comprehensive Performance Evaluation of EnterpriseUniversity-Research Institute Cooperation Innovation, Science \& Technology and Economy, Vol.151 (2013) No.26, p.75.

[9] H.Y. Wu, Y. Wang and M.Q. Wu: Fuzzy Mathematical Model of the University Employment Administration Performance Evaluation, Journal of Shenyang University of Technology, Vol.31 (2012) No.3, p.47, (In Chinese).

[10]W. Luo: Application of Single-chip Microcomputer (People's Posts and Telecommunications Press, China 2010), (In Chinese).

\section{Authors' Information}

Jiangsu University of Technology

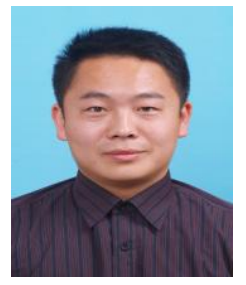

Xiaoyue Wang, male, born in 1984, Changzhou, Jiangsu. He received the master's degree in Computer Technology from Jiangsu University of Science and Technology. He used to be a lecturer at the Institute of Computer Engineering in Jiangsu University of Technology. Currently, he is a teaching management staff in Dean's Office. His interests are in education management, cultivation of talents, talent evaluation, digital teaching resource development and computer technology. 
Jiangsu University of Technology

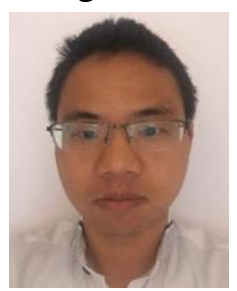

Haixu Xi, male, born in 1981, Jishui, Jiangxi. He received the master's degree in Educational Technology from Nanjing Normal University. Currently, he is a lecturer at the Institute of Computer Engineering in Jiangsu University of Technology. His interests are in cultivation of talents, digital teaching resource development and multimedia technology.

\section{Wuxi Higher Vocational School of Tourism and Commerce}

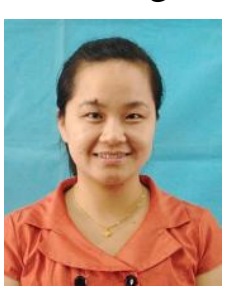

Xinping Hong, female, born in 1977, Wuxi, Jiangsu. She received the bachelor's degree in English Education from Suzhou University and the master's degree from Shanghai Normal University. Now, she is an associate professor in Wuxi Higher Vocational School of Tourism and Commerce. Her interest is in English education and tourism translation. In addition, she has certificates of English tour guide and tour leader, and possesses practical experience in tourism.

\section{Changzhou Vocational School of Industry and Trade}

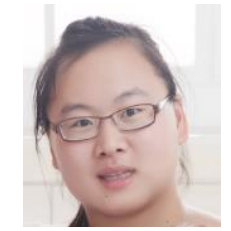

Lijuan Gao, female, born in 1988, Liyang, Jiangsu. She received the master's degree in the Internet of Things Engineering College from Jiangnan University. Currently, she is an assistant lecturer in Changzhou Vocational School of Industry and Trade. Her interests are in digital teaching resource development, network technology and multimedia technology. 